\title{
Varl-SIG 2014 - From SNPs to variants: interpreting different types of genetic variants
}

\author{
Yana Bromberg ${ }^{1,2^{*}}$, Emidio Capriotti ${ }^{3,4,5^{*}}$ \\ From Varl-SIG 2014: Identification and annotation of genetic variants in the context of structure, function \\ and disease \\ Boston, MA, USA. 12 July 2014
}

\section{Introduction}

The decreasing cost of high-throughput sequencing is still rapidly increasing the number of known genetic variants $[1,2]$. For example, the size of the dbSNP database [3] has nearly doubled over the past years to 110 million human single nucleotide polymorphisms and short genomic variants. Unfortunately the characterization, annotation, and interpretation of these variants are still lagging. In particular, the interpretation of genetic variants and their implication in disease is one of the major challenges in personalized medicine [4-6].

The $4^{\text {th }}$ edition of the Variant Interpretation Special Interest Group (VarI-SIG, formerly SNP-SIG) meeting [7-9] was held on July 12 at the ISMB 2014 in Boston (MA). The central meeting themes were "Annotation and prediction of structural/functional impacts of coding variants" and "Genetic variants as effectors of change: disease and evolution". The VarI-SIG is organized as a venue for the development of a research network of scientists, necessary for facilitating the exchange of ideas and establishing new collaborations. This year's meeting attracted over 100 participants, with seven research talks and five presentations from the leading scientists of the field.

\section{Manuscript submission and review}

This year we received 11 submissions to the VarI-SIG special issue. All submissions were by-invitation on the basis of talks/interactions that took place at the meeting. In addition to editorial evaluations, all manuscripts were assessed by at least two reviewers from a panel of 22 experts in the field (see Acknowledgements). To

\footnotetext{
* Correspondence: yanab@rci.rutgers.edu; emidio@uab.edu 'Department of Biochemistry and Microbiology, Rutgers University, 08901 New Brunswick (NJ), USA

${ }^{3}$ Division of Informatics, Department of Pathology, University of Alabama at Birmingham, 619 19th St. South, 35249 Birmingham (AL), USA

Full list of author information is available at the end of the article
}

maintain reviewer anonymity, the four reviewers of submissions in which the editors are co-authors remain un-named. After 2 rounds of review 9 of the 11 manuscripts were accepted for publication in this special issue.

The articles presented in this SIG proceedings issue focus on annotating genomic variants in coding [10] and non-coding regions [11], identifying phenotypic impacts of genetic and epigenetic variations [12-14], characterizing biological basis of Mendelian diseases [15] and interpreting the cancer genome [16], detecting positive selection in regulatory regions [17], and identifying geographical origins of individuals [18].

[The complete program of VarI-SIG meeting 2014 with presentation and poster abstracts is available at http:// varisig.biofold.org/2014/docs/vari-sig-2014-programme. pdf].

\section{Further developments}

This year we welcome to the VarI-SIG organizing committee Dr. Hannah Carter, Assistant Professor, Division of Medical Genetics, UCSD. Together, we are working on the organization of the next VarI-SIG meeting that will be held in the context of the ISMB/ECCB 2015 (Dublin, Ireland; July 11, 2015). Further information about the meeting is available on our website (http:// varisig.biofold.org).

In collaboration with ISMB organizers, we are also promoting the formation of VarI-COSI (Variant Interpretation Community of Special Interest). VarI-COSI is community aimed at sharing relevant information, discussing ideas, and providing training and support networks in the field of genomic interpretation. We are still in the initial stages of setting up our COSI presence on the web and look forward to input and participation from the variation interpretation community. 


\section{Competing interests}

The authors declare they have no conflict of interests in relation to this VarlSIG 2014 special issue article.

\section{Authors' contributions}

YB and EC wrote the manuscript. Both authors read and approved the manuscript.

\section{Acknowledgements}

We are grateful to Rachel Karchin (John Hopkins University, Baltimore, MD) for the organizing and chairing of the MD Corner and roundtable discussion. We thank Frank Schacherer and BIOBASE International for their financial support. We acknowledge Isobel Peters and the editorial staff of BioMed Central for their help with releasing this issue. We would like to extend special thanks for all help to the ISMB organizational committee and specifically Steven Leard and Jeremy Hennig.

We also thank the invited speakers: George Church (Harvard University, Cambrige, MA), Garry Cutting (John Hopkins, Baltimore, MD), Jan Korbe (EMBL, Heidelberg, Germany), James Potash (University of lowa, lowa City IA) and Benjamin Raphael (Brown University, Providence, RI).

Finally, we are very grateful for the patience and help of our colleagues around the world who reviewed the submitted manuscripts. The Varl-SIG 2014 special issue would has not be possible without them:

Francesc Calafell (Universitat Pompeu Fabra, Barcelona, Spain), Hannah Carter (University of California, San Diego, CA), Xavier de la Cruz (Vall d'Hebron Institute of Research, Barcelona, Spain), Paul Geeleher (University of Chicago, Chicago, IL) Christian Gilissen (Radboud University, Nijmegen, Netherland), Alexandra Graf (FH Campus, Wien, Austria), Tae Hyun Hwang (Southwestern University, Dallas, TX), Jose MG Izarzugaza (DTU, Lyngby, Denmark), Martin Kircher (University of Washington, Seattle, WA), Biao Li (Gilead Sciences Inc., Foster City, CA), Yves Lussier (Arizona State University, Tucson, AZ), Ugur Sezerman (Sabanci University, Istanbul, Turkey), Hashem Shihab (University of Bristol, Bristol, UK), Nick Tatonetti (Columbia University, New York, NY), Jacob Tennessen (Oregon State University, Corvallis, OR), Ali Torkanami (Scripps Institute, San Diego, CA), Silvio Tosatto (University of Padova, Padova, Italy), Verena Zuber (University of Oslo, Oslo, Norway) and 4 anonymous reviewers who evaluated the papers where the editors of this special issue are co-authors.

This article has been published as part of BMC Genomics Volume 16 Supplement 8, 2015: Varl-SIG 2014: Identification and annotation of genetic variants in the context of structure, function and disease. The full contents of the supplement are available online at http://www.biomedcentral.com/ bmcgenomics/supplements/16/S8.

\section{Authors' details}

${ }^{1}$ Department of Biochemistry and Microbiology, Rutgers University, 08901 New Brunswick (NJ), USA. ${ }^{2}$ Department of Genetics, Rutgers University, 08854 Piscataway (NJ), USA. ${ }^{3}$ Division of Informatics, Department of Pathology, University of Alabama at Birmingham, 619 19th St. South, 35249 Birmingham (AL), USA. ${ }^{4}$ Department of Clinical and Diagnostic Sciences, University of Alabama at Birmingham, 619 19th St. South, 35249 Birmingham (AL), USA. ${ }^{5}$ Department of Biomedical Engineering, University of Alabama at Birmingham, 619 19th St. South, 35249 Birmingham (AL), USA.

Published: 18 June 2015

\section{References}

1. Capriotti E, Nehrt NL, Kann MG, Bromberg Y: Bioinformatics for personal genome interpretation. Brief Bioinform 2012, 13(4):495-512.

2. 1000 Genomes Project Consortium, Abecasis GR, Auton A, Brooks LD, DePristo MA, Durbin RM, Handsaker RE, Kang HM, Marth GT, McVean GA: An integrated map of genetic variation from 1,092 human genomes. Nature 2012, 491(7422):56-65.

3. Sherry ST, Ward MH, Kholodov M, Baker J, Phan L, Smigielski EM, Sirotkin K: dbSNP: the NCBI database of genetic variation. Nucleic Acids Res 2001, 29(1):308-311.

4. Fernald GH, Capriotti E, Daneshjou R, Karczewski KJ, Altman RB Bioinformatics challenges for personalized medicine. Bioinformatics 2011, 27(13):1741-1748

5. MacArthur DG, Manolio TA, Dimmock DP, Rehm HL, Shendure J, Abecasis GR, Adams DR, Altman RB, Antonarakis SE, Ashley EA, et al:
Guidelines for investigating causality of sequence variants in human disease. Nature 2014, 508(7497):469-476.

6. Bromberg Y: Building a genome analysis pipeline to predict disease risk and prevent disease. J Mol Biol 2013, 425(21):3993-4005.

7. Bromberg Y, Capriotti E: SNP-SIG Meeting 2011: identification and annotation of SNPs in the context of structure, function, and disease. BMC Genomics 2012, 13(Suppl 4):S1.

8. Bromberg Y, Capriotti E: Thoughts from SNP-SIG 2012: future challenges in the annotation of genetic variations. BMC Genomics 2013, 14(Suppl 3): S1.

9. Bromberg Y, Capriotti E: SNP-SIG 2013: from coding to non-coding-new approaches for genomic variant interpretation. BMC Genomics 2014, 15(Suppl 4):S1.

10. Hecht $M, B$ Bromberg $Y$, Rost B: Better prediction of functional effects for sequence variants. BMC Genomics 2015, 16(Suppl 8):S1.

11. Frankish A, Uszczynska B, Ritchie GRS, Gonzalez JM, Pervouchine D, Petryszak R, Mudge JM, Fonseca N, Brazma A, Guigo R, Harrow J: Comparison of GENCODE and RefSeq gene annotation and the impact of reference geneset on variant effect prediction. BMC Genomics 2015, 16(Suppl 8):S2.

12. Ma M, Ru Y, Chuang LS, Hsu NY, Shi LS, Hakenberg J, Cheng WY, Uzilov A Ding W, Glicksberg BS, Chen R: Disease-associated variants in different categories of disease located in distinct regulatory elements. BMC Genomics 2015, 16(Suppl 8):S3.

13. Pal LR, Yu C-H, Mount SM, Moult J: Insights from GWAS: emerging landscape of mechanisms underlying complex trait disease. BMC Genomics 2015, 16(Suppl 8):S4

14. Gnad F, Doll S, Manning G, Arnott D, Zhang Z: Bioinformatics analysis of thousands of TCGA tumors to determine the involvement of epigenetic regulators in human cancer. BMC Genomics 2015, 16(Suppl 8):S5

15. Di Lena P, Martelli PL, Fariselli P, Casadio R: NET-GE: a novel NETworkbased Gene Enrichment for detecting biological processes associated to Mendelian diseases. BMC Genomics 2015, 16(Suppl 8):S6.

16. Tian R, Basu MK, Capriotti E: Computational methods and resources for the interpretation of genomic variants in cancer. BMC Genomics 2015, 16(Suppl 8):S7.

17. Handelman SK, Seweryn M, Smith RM, Hartmann K, Wang D, Pietrzak M, Johnson AD, Kloczkowski A, Sadee W: Conditional entropy in variationadjusted windows detects selection signatures associated with expression quantitative trait loci (eQTLs). BMC Genomics 2015, 16(Suppl 8):S8.

18. Kozlov K, Chebotarev D, Hassan M, Triska M, Triska P, Flegontov $P$ Tatarinova TV: Differential Evolution approach to detect recent admixture. BMC Genomics 2015, 16(Suppl 8):S9.

doi:10.1186/1471-2164-16-S8-I1

Cite this article as: Bromberg and Capriotti: Varl-SIG 2014 - From SNPs to variants: interpreting different types of genetic variants. $B M C$ Genomics 2015 16(Suppl 8):11.

\section{Submit your next manuscript to BioMed Central and take full advantage of:}

- Convenient online submission

- Thorough peer review

- No space constraints or color figure charges

- Immediate publication on acceptance

- Inclusion in PubMed, CAS, Scopus and Google Scholar

- Research which is freely available for redistribution

Submit your manuscript at www.biomedcentral.com/submit
C Biomed Central 